Article

\title{
Proposing a Value-Based Digital Government Model: Toward Broadening Sustainability and Public Participation
}

\author{
Jungwoo Lee ${ }^{1}{ }^{(\mathbb{C}}$, Byoung Joon Kim ${ }^{2, *(\mathbb{D})}$, SeonJu Park ${ }^{3}$, Sungbum Park ${ }^{4}$ and Kangtak Oh ${ }^{5}$ \\ 1 Graduate School of Information, Yonsei University, Seoul 03722, Korea; jlee@yonsei.ac.kr \\ Department of Public Administration, Kookmin University, Seoul 02707, Korea \\ Department of e-Government, National Information Society Agency, Daegu 41068, Korea; sjpark@nia.or.kr \\ Graduate School of Management of Technology, Hoseo University, Asan-si 31499, Korea; parksb@hoseo.edu \\ 5 Department of Global ICT Cooperation, National Information Society Agency, Daegu 41068, Korea; \\ okt@nia.or.kr \\ * Correspondence: kimbj@kookmin.ac.kr; Tel.: +82-2-910-5627
}

Received: 22 July 2018; Accepted: 27 August 2018; Published: 29 August 2018

check for updates

\begin{abstract}
It has generally been well-established, by a number of studies, that the rapid advance and global diffusion of information and communication technology (ICT) is impacting the milieu of governance along with a socio-technical transformation of society at all levels. With a growing interest in digital government, the inquiry concerning a common digital model has been raised. To assist public administrators in thinking about new digital government for their organizations, a new developmental model framework is proposed in this article. This model is drawn from value-based analysis contained in developmental policies, and a subsequent policy development process is also proposed. In doing so, the new model would represent accelerated socio-technical transformation with intelligent technologies, escalating wicked problems appearing despite technological advances. The limitations of the current finite state model are also discussed.
\end{abstract}

Keywords: digital government; public value; developmental model; governance; data

\section{Introduction}

Governments worldwide began using information and communication technology (ICT) for their operations since its advent in the 1970s and 1980s. However, developing and implementing digital government are value-laden activities that are handled and carried out by citizens [1-5]. In this regard, with the rapid advance of ICT, the values attached to government utilization of ICT have continuously evolved. Until the 1990s, the operational level of efficiency in governments increased, as did transparency and accountability [6-9]. In the 2000s, with the advent of the Internet, the values emphasized were trust and cooperative governance. In the 2010s, with the advancement of smart devices and fast networks, the focus on using digital government to increase productivity in the public sector, such as using ICT for the automation and informatization of government operations, has been shifting toward achieving sustainability for the next generation [10-14].

This evolution is also apparent in the modelling of digital government. Initially, the focus was on the technological side, while later models focused on the institutional aspects beyond technology [10-16]. With the recent shift of public value focus from efficiency toward the "effective" achievement of sustainable development goals, it is evident that the current digital government model does not suffice in its role in guiding future development of digital government. A future-oriented model of digital government guiding further efforts in the socio-technical transformation of governments as well as society is needed. In other words, authors provide a normative direction 
of the future model of digital government. Three critical reasons for developing a new value-based digital government (VDG) model are as follows: (1) accelerated socio-technical transformation with intelligent technology, (2) escalating wicked problems despite technological advances, and (3) the need to address the limitations of the current finite state model.

Therefore, in this paper, a new model of digital government for enhancing sustainability and public participation for the future generation is proposed. The model should be aligned with a public-valued-based approach, which is represented by the acceleration of socio-technical transformation with intelligent technologies, resolving wicked problems appearing despite technological advances. Also, the limitations of the current finite state model are also discussed for embracing the meaning of elements of previous e-Government models via a dialectic approach.

\section{Drivers of New Value-Laden Digital Government}

\subsection{Accelerated Socio-Technical Transformation with Intelligent Technologies: New Environment}

The technological environment around digital government has continuously been changing in an accelerated manner. Especially since the Internet revolution in the 2000s and smart device proliferation in the 2010s, the rapid advance and global diffusion of ICT has been practically impacting the milieu of governance along with the socio-technical transformation of society at all levels. The recent advent of ICBM (IoT, Cloud, Big Data, and Mobile) as well as artificial intelligence (AI) provides infinite possibilities for intelligent information technology worldwide.

These intelligent information technologies are expected to lead the 4th industrial revolution, as proposed in the World Economic Forum at the beginning of 2016 [17], leading to a rather radical revolution of authors' work, life, and governance from the bottom. These technological innovations have that fundamentally changed the current work and life paradigm will move the foundation of economic and social systems at a level not previously experienced in terms of scale, scope, and complexity [18]. It has been predicted that an autonomous pull economy will soon emerge through seamless integration of the cyber world with the real world, and differentiations between products and services, consumers and producers, and production means and production scope will become meaningless [19]. In context of governance, this can be related to the disappearance of boundaries between the public and private sectors and between governments and citizens [20-25].

With the new generations of ICT, it is suggested that its strategic use in government-i.e., digital government-is to be directed to cover more dimensions than simple integration issues and/or supportive functions of government services primarily provided by technology [26-29]. In this regard, a new digital government model needs to capture the future use of ICT.

Fast and practical transformation into a socio-technical paradigm will dramatically change the environment of digital government operations as well as the embedded values and goals [30]. Abundant data and information resources resulting from connecting things in the world, $\mathrm{O} 2 \mathrm{O}$ (Online to Offline) convergence, will drastically increase the accessibility of digital government [31]. Digital government will be expected to provide and realize digital benefits to all constituents beyond the simpler automation of service delivery and replication of government services in the virtual world.

\subsection{Escalating Wicked Problems Despite Technological Advances: Need for Targeted Policy Instrumentations}

Developing information systems, including digital governments, is largely dependent on a problem-solving approach. From a requirement toward the design of systems, the whole process of public service delivery is known to address problems that are solvable with ICT. However, most problems addressed by digital government until now seem to be geared toward smaller-scale problems, such as ones related to citizen service delivery and efficiencies of governmental operations. Despite the immense technological advances in ICT, wicked problems seem to be increasing and escalating in the real world [32-35]. This appears paradoxical as ICT has been described as a tool to 
solve problems that we face and to improve our living conditions, thereby making the world a better place for us.

Wicked problems are contrasted with conventional problems that can be solved with methodical approaches in the public sector. A number of critiques have emerged concerning the rational-technical approaches to complicated issues of public policy programs, such as education, poverty, housing, and unemployment problems, in which coordination and goal-clarification among diverse stakeholders are too difficult to obtain [32,33]. It has been suggested that we are living in an age where the number of wicked problems is increasing significantly [36]. Concerns about wicked problems have been raised in dealing with an increasing number of disasters and crises.

It seems that wicked problems are becoming more complicated while demands for policy instrumentations to address them are becoming diverse and segmented [37]. In this regard, forecasting policy demand and prescribing for the future should be a digital government's goal in addressing these wicked problems, beyond the efficient operational service delivery that we have focused on until now. Thus, the new model of digital government, VDG, thus needs to employ a different approach to those used in the current models. As the focus of VDG, henceforth, would rather be wicked problem-solving, it is natural for the goal of VDG to be aligned with sustainable development goals announced by the United Nations (UN) in 2015. Thus, this new VDG model will be based on a framework for addressing wicked problem-solving geared toward the sustainable development goals of people.

\subsection{Limitations of the Finite State Model: Need for a Continuous Model}

Most of the currently available digital government models appear to be designed as a finite state machine, in which there are different stages of developments or different combinations of components. For example, the UN model, which was used in evaluations for a worldwide e-government index and ranking, presents concrete measures defining different stages or states. A close inspection of these measures has revealed that the difference in first and second place in the ranking is determined by minute differences in numbers [38]. Advanced countries in this ranking, which have reached the final state as defined, may have different orientations in designing and developing digital governments; even though they are in a similar state according to this model, the value that they are looking for is different.

These finite state models of digital government that have been used to guide the development of digital governments lose their merits when nations enter the final state, as the final state does not represent a perfect fulfilment of value inherently designed in a digital government. We need guidelines beyond the final state, looking at the future. We are dealing with mature technology that can be converged and manipulated in ways that we desire.

As the finite model assumes that there is an ultimate state, its use is not appropriate in the context of continuously evolving phenomena, such as digital government, because technology will evolve along with social and institutional transformations reciprocally. It would not be predictable as much as the future of mankind. In this regard, the new digital government model becomes a reference model rather than a concrete finite state model.

\section{Conceptualizing the New Digital Government Model: What Is New?}

As briefly mentioned in the previous section, the e-government models developed and used until now may lack some features necessary to frame the future of digital government. Most e-government models use a micro-level approach emphasizing technology and service with a close focus on the operational efficiency of government services. To step beyond this micro-focus, a new VDG model is developed and presented here. 


\subsection{Current e-Government Models}

A careful review of approximately 50 digital government models (The models were reviewed in this paper as follows: Layne and Lee Maturity Model (2001), Andersen and Heriksen Maturity Model (2006), UN Maturity Model (2012), Alhomod et al. Maturity Model (2012), Hiller and Belanger Maturity Model (2001), Almazan and Gil-Garcia Maturity Model (2006), Cisco Maturity Model (2007), Gartner Group Model-Baum and Di Maio (2000), Gartner Group Maturity Model (2010), Gartner Group Open Government Maturity Model-Lee and Kwak (2012), West Maturity Model (2004), Moon Maturity Model (2002), World Bank Maturity Model (2003), Deloitte and Touche Maturity Model (2000), Howard Maturity Model (2001), Shahkook et al. Maturity Model (2008), Siau and Long Maturity Model (2005), Wescott Maturity Model (2001), Chandler and Emanuel Maturity Model (2002), Kim and Grant Maturity Model (2010), Chen Maturity Model (2011), Windley Maturity Model (2002), Reddick Maturity Model (2004), Accenture Maturity Model-Rohleder and Jupp(2003), UK National Audit Maturity Model (2002), Netchaeva Maturity Model (2002), EU Maturity Model-Colclough and Tinholt (2009), EU Future e-Government Model (2007), OECD Model (2008), NIA stage Model (2016), Japan Stage Model (2015), OEDC data value cycle Model (2015), White House Model (2013), Heeks and Bhatnagar Model (1999), Heeks Onion Ring Model (2006), NIA-S. T. Kim Model (2003), NIA-G. T. Oh Model (2003), S. H. Kim Gov 3.0 Model (2014), UNESCAP e-Governance Model (2005), Estevez and Janowski Sustainable Development Model (2013), Digital Government Evolution Model-Janowski (2015), Frissen and Millard Model (2007), Grönlund Model (2009), Meta-Synthesis Model-Lee (2010), e-Government Adoption Model-Mahmud et al. (2011), e-Government Development Model-Norman and Hebbar (2016), Global e-Governance Model-Kim (2013), IBM e-Government Model (2003), PWC e-Government Model (2002), Ernst \& Young e-Government Model (2003)), which have been popularly used and mostly quoted since 2000 , revealed two streams in terms of conceptualizing digital government models. One is the staged maturity model, and the other is the component model. Earlier models were designed for stage maturity levels in terms of their technology implementations. These stage models adopt technology-related terminologies, such as presence, transaction, integration, and convergence.

Comparatively, component-based models were developed much later to expand the horizon of digital government once technological development reached some maturity. These models were targeted to describe the dynamic relationship among components of digital government to develop concrete strategic directions beyond technology implementation. Thus, their terminology, generally, covers areas other than technology, such as e-democracy, service, governance, human resources, participation, and empowerment.

The models that have been developed and used until now are either based on maturity or components. They seem to be limited in terms of providing future-oriented perspectives due to the following characteristics:

- Micro-level approach emphasizing technology and service

- Operational efficiency orientation

- Policy-assessment-focused framework

First, most of the current models are based on a micro-level approach that emphasizes technology and service. Both stage and component models position technology as the core influential variable affecting the service levels of government and degree of technological advancement of government. When viewed in detail, the staged maturity model appears to use technology-centric approaches, while component-based models include concepts other than technology, such as process, organization, human resources, and governance, further reflecting the multi-dimensional nature of digital government.

Second, most of the current models are oriented toward the operational efficiency of government and optimization of service operations for citizens. The current digital government models tend to emphasize the efficiency of administrative services online. 
Third, existing models are mostly piecemeal troubleshooting models rather than ones focused on solving wicked problems. They are used to evaluate service improvement quantitatively. In this regard, the models that have been developed and used until now are either based on maturity or components. They appear limited in terms of providing future-oriented perspectives.

Considering these limitations, this study equally emphasizes governance and people as the main component of the VDG along with the current components of technologies, data, and services. Through these five components, governments are now expected to solve wicked problems for each key area of sustainable growth that digital government aims to achieve.

\subsection{Strategic Directions of New Digital Government Model Development}

In the new digital government model, developed in this research, concerted efforts were made to overcome the limitations of the current models by devising a macro-level approach. With a new orientation toward public value and expectations targeted to solve wicked problems and to achieve sustainable development goals as an integrative reference model beyond the finite state model, the new model is explained below (see the Figure 1).

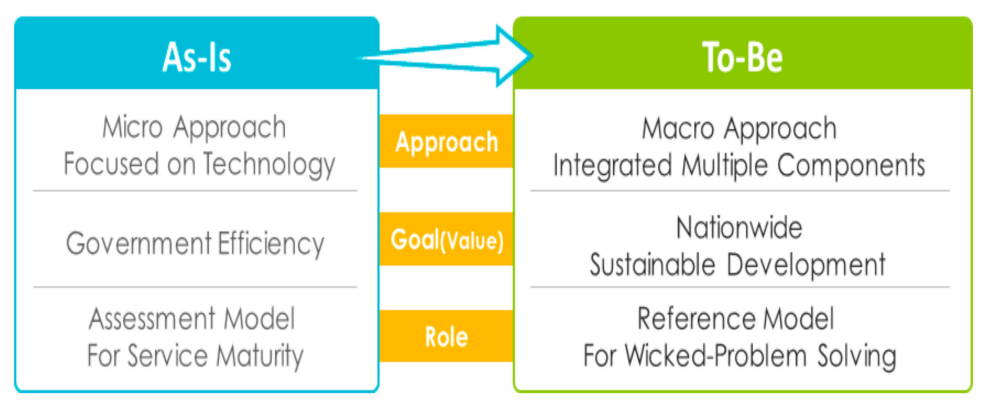

Figure 1. Characteristics of New Digital Government.

First, value-based digital government (VDG) demands a macro-level approach that goes beyond the current technology-focused micro approach. Fast advancing technologies as well as the accompanying social technical revolution requires long-term insights that can take into consideration current financial resources. Also, to address increasingly complicated wicked problems within these social technical changes, the new digital government model needs to include social and organizational factors beyond technology and service, such as human resources and governance. In this regard, VDG components should be identified and defined at a scale larger than just technology.

Second, compared to current models, which are targeted mostly toward enhancing governmental efficiency and increasing the quality of public service using ICT, the VDG model focuses on the sustainable development of society and nations. Since 2015, sustainable development goals have been proposed as those of the UN subsequent to millennium goals. These goals provide basic visions for the desirable future of mankind. As digital governments are expected to become a new paradigm of governance, sustainable development of a society as well as a nation seems to be an appropriate target value.

Finally, the VDG model is expected to adopt a new role beyond an assessment framework because of the extent of digitalization of service the government has achieved or the number of changes made in the ways of work. The VDG model is expected to provide an integrative reference model in which innovations in the elements of digital government, such as data, technology, service, human resources, and governance blend interdependently to solve various wicked social problems.

\subsection{Purposefully Targeting the VDG Model for Enhancing Sustainability}

The new digital government model that is under development is based on a problem-solving framework, specifically for wicked problems, which require a wider scope than localized problems. 
The resulting VDG model is a focused reference model targeted to augmenting and supporting the sustainable development goals recently identified by the UN. It largely consists of two parts: targeting problems and devising solutions for sustainable development as presented in Figure 2. Four target areas of wicked problems are designed to be identified in this framework at the initial stage of problem-solving using this reference model. The four target areas are the levels of (1) individuals, (2) society, (3) nation, and (4) inter-nation.

The conceptual relationship between the four target areas and the reformed sustainable development is presented in Figure 2. As part of the new VDG model, potential and integrative solutions, by combining elements of digital governments, for each of the four target areas are proposed. Sustainable development goals are partly achieved and supported via this problem-solving mechanism.

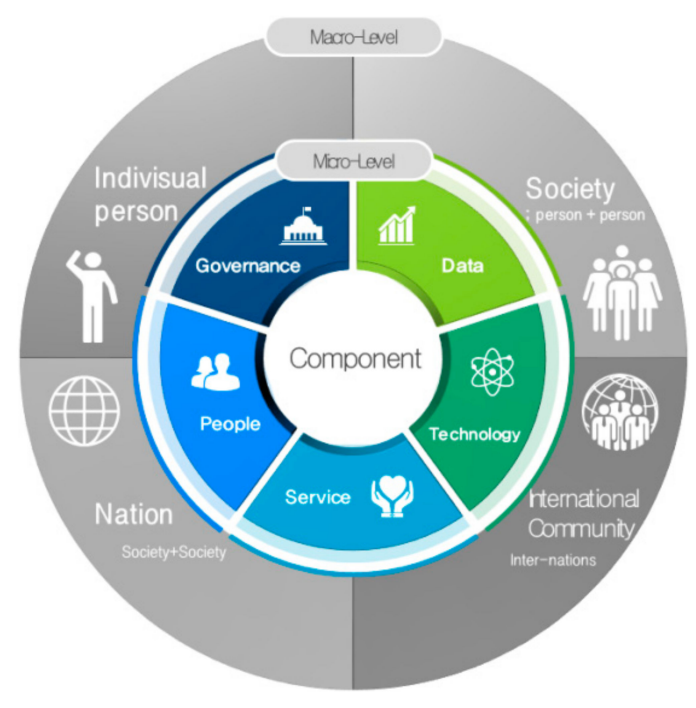

Figure 2. Four Target Areas (Macro-Level) and Five Critical Elements (Micro-Level).

\section{Case Study: South Korea}

In this section, an example of using the new VDG modeling approach is presented following the aforementioned steps. Yearly reports from different government functions are collected as an initial qualitative dataset for identifying problems recognized by different governmental functions. These problems are clustered into larger problems simulating the underlying structure of wicked problems faced by the Korean government. Using the Data, Technology, Service, People, and Governance (DTSPG) framework, feasible integrative solutions are identified and presented as an example.

Identifying issues and problems: as the key issues in the four target subjects pursued by the VDG model, we derived issues that the Korean government needs to focus on. Through literature reviews, such as UN Sustainable Development Goals (SDG)'s 17 agenda, a variety of issues and problems of the international community were expanded and added.

However, we tried to identify issues that can be applied to the international community rather than South Korea's domestic-specific issues, especially in cases of conducting text-analysis of the three-year master plans in 17 ministries of central government. Common issues that concern numerous countries are considered with higher priority. Thereafter, a survey was administered targeting more than 300 experts of digital government in South Korea for cross-validation checks with the text-analysis. The survey questioned the appropriateness of connections between problems and solutions Table 1.

Finally, a total of 74 governmental problems were derived with respect to the four targets, and they have been classified below. The selected problems were limited to ones with a long-term perspective (for the next five years) in terms of urgency and ripple effects. As a result of problem-solving, they were classified by "individual" (13), "society" (29), "nation" (24), and "inter-nation" (8). 
Table 1. Governmental Problems Identified.

\begin{tabular}{|c|c|}
\hline Subject & Keywords Regarding the PROBLEM ${ }^{1}$ \\
\hline Individual (13) & $\begin{array}{l}\text { (1) increase in the burden of entrance examination } \\
\text { (2) burden of life extension anxiety and its cost-bearing } \\
\text { (3) workers compensation issues } \\
\text { (i.e., a small salary for the working class in Korean society) } \\
\text { (4) lack of leisure and cultural infrastructure } \\
\text { (5) career-decision mentoring problem } \\
\text { (6) increase of citizens' safety ignorance } \\
\text { (7) shortage problem of low-income housing } \\
\text { (8) failure of human rights protection } \\
\text { (9) failure of consumer rights protection } \\
\text { (10) growing problem of domestic violence/juvenile delinquency } \\
\text { (11) privacy protection issues } \\
\text { (12) escalation of the household's financial cost } \\
\text { (13) public welfare policy and law enactment proposing issues }\end{array}$ \\
\hline Society (29) & $\begin{array}{l}\text { (1) insufficient educational policy reflecting social demand } \\
\text { (2) job instability } \\
\text { (3) insufficient job creation } \\
\text { (4) deepening youth unemployment } \\
\text { (5) unemployment crisis among high school graduates } \\
\text { (6) unemployment crisis among vulnerable social groups } \\
\text { (7) absence of a women's social activities system } \\
\text { (8) demand on the vitalization policy of the "new industry" } \\
\text { (9) increasing traffic congestion } \\
\text { (10) insufficient protection policy for the socially weak } \\
\text { (11) issues on broadcasting harmfulness } \\
\text { (12) appropriateness issues in the content review system } \\
\text { (13) issues on online/offline violence } \\
\text { (14) matters on juvenile protection } \\
\text { (15) worsening of low birth and aging problems } \\
\text { (16) lack of countermeasures for the digital content market crisis } \\
\text { (17) devitalization of local tourism } \\
\text { (18) economic deflation } \\
\text { (19) demands to beef up the industry } \\
\text { (20) lack of technology and academic achievement management capacity } \\
\text { (21) demand for an industrial accident prevention measure } \\
\text { (22) issues on unfair business practices } \\
\text { (23) lack of conflict management } \\
\text { (24) worsening of conflict labor management } \\
\text { (25) worsening of regionalism } \\
\text { (26) severe disproportion between regions } \\
\text { (27) support for rural development } \\
\text { (28) demands on the win-win type corporate ecosystem } \\
\text { (29) demands on reforming the college entrance-exams-focused educational system }\end{array}$ \\
\hline Nation (24) & $\begin{array}{l}\text { (1) deferred public administrative process due to the sectionalism in government ministry } \\
\text { (2) sluggish correspondence on domestic and foreign environmental change } \\
\text { (3) lack of inter-ministry collaboration } \\
\text { (4) insufficient deregulation and institutional improvement } \\
\text { (5) opaque policy-enacting process } \\
\text { (6) inappropriate public relations policy } \\
\text { (7) low sensory level of government policy } \\
\text { (8) lack of government operation/managing performance } \\
\text { (9) spate of corruption } \\
\text { (10) restructuring and reforming of the educational system } \\
\text { (11) insufficient global regulatory reforms for innovation } \\
\text { (12) insufficient education policy operations } \\
\text { (13) insufficient improvement of policy on working hours } \\
\text { (14) insufficient human resource development } \\
\text { (15) insufficient company foundation support } \\
\text { (16) insufficient welfare policy and services } \\
\text { (17) lack of childcare support } \\
\text { (18) vitalization of science and technology research and development (R\&D) } \\
\text { (19) increased occurrence of disasters } \\
\text { (20) lack of environmental improvements } \\
\text { (21) insufficient benefits for citizens }\end{array}$ \\
\hline
\end{tabular}


Table 1. Cont.

\begin{tabular}{|c|c|}
\hline Subject & Keywords Regarding the PROBLEM ${ }^{1}$ \\
\hline & $\begin{array}{l}\text { (22) increased domestic greenhouse gas emissions } \\
\text { (23) insufficient regional development policy } \\
\text { (24) lack of fiscal crisis preparedness and management system }\end{array}$ \\
\hline Inter-Nations (8) & $\begin{array}{l}\text { (1) lack of international cooperation on apprehending overseas criminals } \\
\text { (2) issues on international cultural content exchange } \\
\text { (3) information demand increase and deepening awareness gap caused by the expansion of } \\
\text { cultural globalization } \\
\text { (4) increase of globalization and movement of labor market } \\
\text { (5) air pollution (including the global warming issue and greenhouse gas problem) } \\
\text { (6) inter-Korean confrontation (including the nuclear issue) } \\
\text { (7) lack of countermeasures on international situation changes (emerging diseases, job crunch) } \\
\text { (8) downturn in national competitiveness due to long-term international recess }\end{array}$ \\
\hline
\end{tabular}

${ }^{1}$ The problems were selected based on official documents of government and classified by digital governments in South Korea. Among these real problems, five questions were selected and applied in the value-based digital government (VDG) model to show the validation of the model.

Clustered into the wicked problem sets: subsequently, five problems were allocated by experts of digital government in South Korea into the final four targeted areas, with five problems. Devising VDG Solutions (with Data, Technology, Service, People, and Governance: DTSPG) for the problems in the VDG model is shown in the table below. In particular, ideas for solutions were provided by a text-analysis of government policy documents from ministries. They were complemented by an AHP-Delphi survey through 20 national and international senior-level digital government experts. Furthermore, when problems for the four target areas are resolved, future images to contribute to sustainable development are presented.

These example sustainable values were identified by experts and public practitioners of digital government in South Korea. For synchronizing with SDGs and values, due to time constraints, not all example solutions are analyzed in depth. For example, problems identified in the area of education are clustered into wicked problems, and DTSPG solutions are devised, presented, and further linked to sustainable development goals as presented in Figure 3.

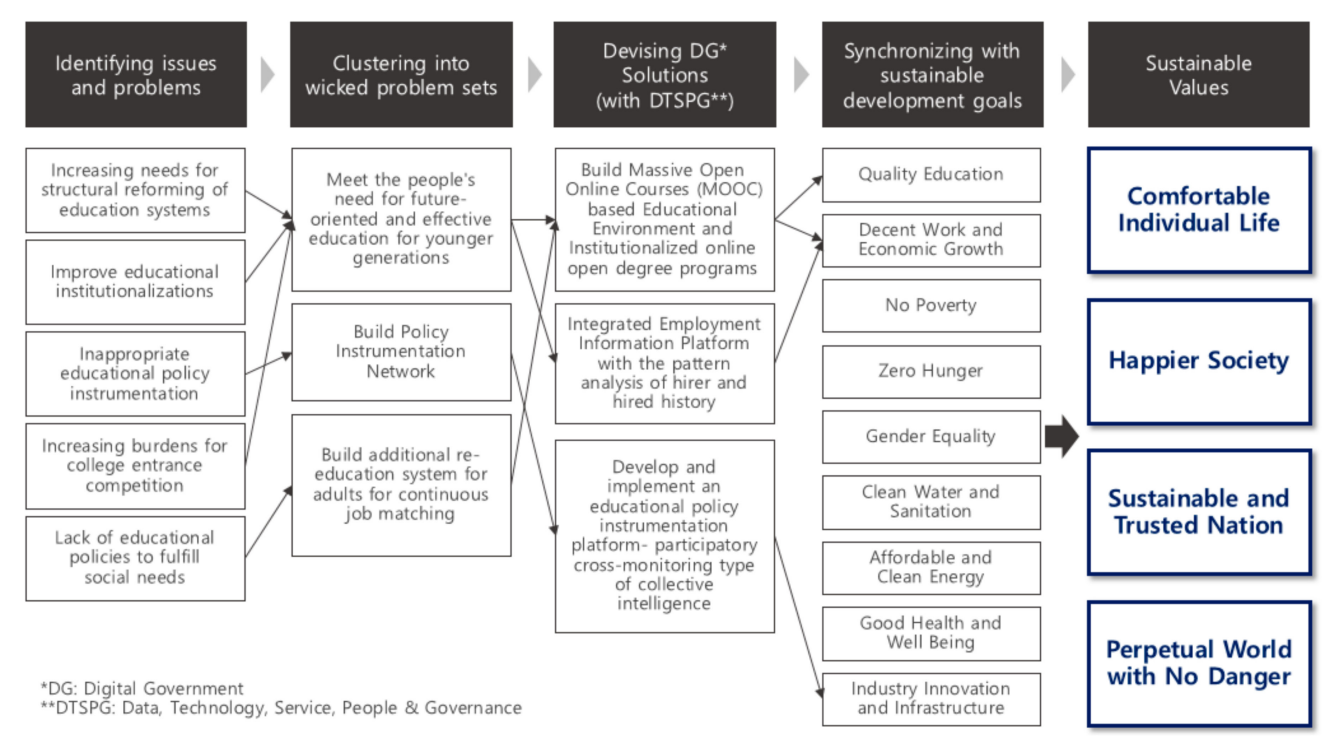

Figure 3. Example of Applying the New Digital Government Model in South Korea. 


\section{New Digital Government Model: Value-Based Digital Government}

The new digital government model consists of two levels: macro and micro. Awareness of problems at the macro-level conceptually leads to the development of integrative solutions by converging five different but related components of digital government. Devised integrative solutions are not only the combination of technologies and services but also the results of combining organizational, institutional, procedural, and societal factors. This new yet flexible digital government model is not a finite state model presenting levels and fixed solutions, but a reference model providing a conceptual basis of thinking for resolving current social and wicked problems in the context of digital government, targeted to achieve sustainable development goals effectively.

Five critical elements of digital government have been identified after carefully reviewing models that have emerged during the last few decades, including those the UN survey is based on. They are data, technology, service, people, and governance. It is also recognizable that digital government models in the early 2000s mostly focused on merely technology, but later models had shifted their focus toward the micro level of elements other than technology, such as people and governance. For example, the UN e-government survey 2016 is composed of two indices: development and e-participation. However, when it began in 2001, it had only one dimension: a staged index for measuring technological development. In this regard, as the baseline of the digital government model, five elements are identified.

It is observed, from reviewing the history of digital government that these elements have evolved dynamically with the advance of technology. The historical progression of each element is conceptualized, based on a review of related reports and articles, as presented in the Figure 4.

Data: Scattered data from the 1970s and 1980s were gathered into locally centralized databases for different government functions in the 1990s. Later, these localized databases were connected and converged to each other due to the synergistic nature of data. The orientation of development has been to integrate and link.

Technology: Support for technologies advanced from simple programming in the 1970s and 1980s to separating data into databases in the 1990s. Later, with the advent of network connections and the Internet, platform installations across functions became technologically feasible. The orientation has been to adopt and utilize technologies.

Services: Information systems were initially implemented to support service routines, but the focus had shifted toward replicating these routines in systems. Later, when re-engineering was trending, the focus shifted toward service transformation, such as enterprise architecture (EA) (to enlarge the digital transformation in public services, the notion of enterprise architecture (EA) contributed to the progression. Thus, EA is more likely to be a good example for the orientation of the service element) and into developing new converged services across different departments and functions. The orientation has been to adapt and be flexible.

People: Focus has shifted from the utilization of tasks that people performed, via digital literacy and informatization, into knowledgification of work and processes. The orientation has been to free people from boredom and burdens and encourage them to be creative.

Governance: Since the advent of digital government, the focus of governance has shifted from rules and police, via transactions, services, interactions, and satisfaction, into co-creating and participating. The orientation has been for governments to be open and let people participate in policy-making processes.

In the future, to improve the execution of the aforementioned solution, it is necessary to accumulate experience and know-how and for nations to share their experiences related to ongoing problems and their desired solutions. In addition, concerns about how to make the most of these elements required for policy inaction are needed. For example, as shown below, components (data, technology, services, human resources, etc.) that will be driving forces in the new model's development direction and further studies, such as how to establish a reciprocal role between them, will have to be supplemented. 


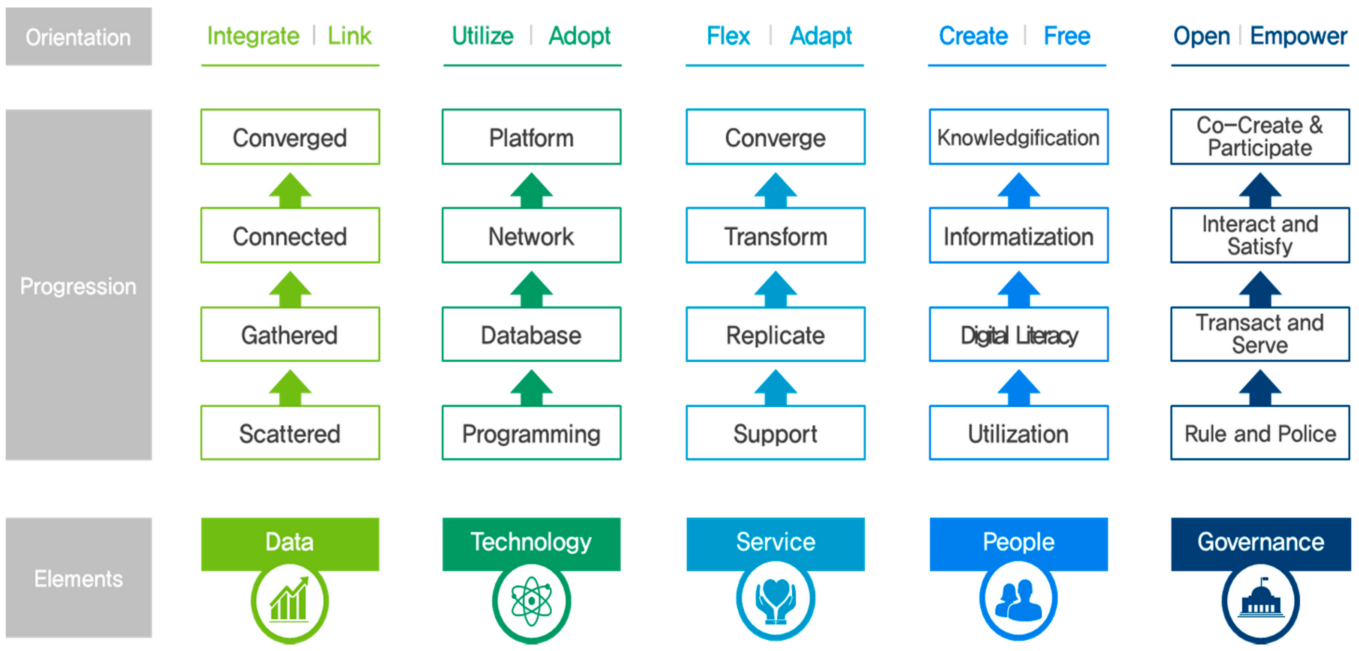

Figure 4. Five Critical Elements of Digital Government (Data, Technology, Service, People, and Governance, DTSPG).

\section{Concluding Remarks}

Most of the current digital government models have been used as bases of developing an assessment framework. As these models were finite state models, the assessment frameworks, in general, are designed as staged maturity models in which digital governments are expected to make progressions through these staged maturity levels.

However, henceforth, from the perspective of advanced nations, as the future of digital government is not clear enough to be defined as a finite states set, the future depends not only upon the advancement of technology but also on devising appropriate governance and people.

As the future of digital government is not definable as a finite state, the framework presented in this VDG model would rather be used as a qualitative tool for assessing people's efforts to conceptualize integrative solutions addressing wicked problems that they are facing.

Problems that have been addressed by e-governments were rather minute and localized, related to process refinements and operation optimization. As advanced nations have succeeded in achieving a mature state of ICT use in government, it is time for us to think about and conceptualize ICT solutions to be used in solving escalating wicked problems in the public sector. The new VDG model will be a good basis for developing a qualitative assessment framework for digital government efforts in terms of sustainability and public values.

In addition, developed nations, the $\mathrm{UN}$, and other international organizations can easily use the model for designing strategies to solve practical policy issues in their efforts to realize sustainable development. For other countries, it can be benchmarked as a future-oriented model when establishing a digital government road-map suited to their country-specific situations.

Further, unlike previous models, the VDG model can become a driver for new roles and expand the functions of digital government by providing the impetus for cooperation opportunities. The new model will also devise initiatives as a strategic tool enabling collective consultation and response to common problems at a pan-global level, going beyond government innovation and solutions to social issues.

Finally, the VDG model proposed here is differentiated from the existing digital government models that have government efficiency as the key incorporation goal. The VDG claims to be an integrated "problem-solving" model with a macroscopic viewpoint pursuing sustainable growth of a national society as its ultimate goal. In this sense, VDG focuses on data, people, and governance as the core components from the technology- and service-oriented short-sighted view and on the dynamic interactions among them. To develop the new digital government model, we conducted literature reviews at home and abroad, 
expert surveys, and focus group interviews. By integrating them, we suggest a commonly available consulting framework and usage scenarios enabling "capability evaluation" on the five key components of digital government (data, technology, service, people, and governance) to "problem-solving" for four major policy target subjects (individual, society, nation, inter-nation).

Ultimately, through the above usage scenarios, this model is expected to contribute toward the creation of a digitally connected, happy global community by helping achieve the implementation objectives of the four target subjects as well as global sustainable development and public participation. In the future, the VDG model could be continuously revised and improved through a process of sharing experiences of using the VDG model among international organizations, developed nations, research institutes, and so forth. In addition, as new problems and solutions are accumulated through this process, we can expect it to be disseminated as a reference model to be used in implementing effective and systematic future digital government. Also, it is expected that nation-specific customized VDG models will be developed for countries with their own differentiated situations of core government components and target problems.

Author Contributions: The five authors contributed equally to this work.

Funding: This research was funded by National Information Society Agency in Korea.

Conflicts of Interest: The authors declare no conflict of interest.

\section{References}

1. Ahmed, M.A.; Janssen, M.; van den Hoven, J. Value Sensitive Transfer (VST) of Systems among Countries. Int. J. Electron. Gov. Res. 2012, 8, 26-42. [CrossRef]

2. Al Rawahi, K.; Coombs, C.; Doherty, N. The Realization of Public Value through E-government: A Structuration Perspective. In Proceedings of the 37th International Conference on Information Systems (ICIS 2016), Dublin, Ireland, 11-14 December 2016; pp. 1-10.

3. Aladalah, M.; Cheung, Y.; Lee, V.C.S. Delivering Public Value: Synergistic Integration via Gov 2.0. In Proceedings of the IEEE 49th Hawaii International Conference on System Sciences (HICSS-49), Kauai, HI, USA, 5-8 January 2016; pp. 3000-3009.

4. Bannister, F.; Connolly, R. Transformation and Public Sector Values. In Electronic Government and Electronic Participation: Joint Proceedings of Ongoing Research and Projects of IFIP WG 8.5 EGOV and ePart 2011; Janssen, M., Macintosh, A., Scholl, H.J., Tan, Y., Eds.; Trauner: Delft, The Netherlands, 2011; Volume 37, pp. 231-239.

5. Bannister, F.; Connolly, R. ICT, public values and transformative government: A framework and programme for research (in English). Gov. Inf. Q. 2014, 31, 119-128. [CrossRef]

6. Bannister, F.; Grönlund, Å. Information Technology and Government Research: A Brief History. In Proceedings of the 50th Hawaii International Conference on System Science (HICSS-50), Waikoloa Village, HI, USA, 4-7 January 2017; pp. 2943-2952.

7. Grönlund, Å.; Horan, T.A. Introducing e-Gov: History, Definitions, and Issues. Commun. Assoc. Inf. Syst. 2005, 15, 713-729.

8. Jæger, B.; Löfgren, K. The history of the future: Changes in Danish e-government strategies 1994-2010. Inf. Polity 2010, 15, 253-269.

9. Relyea, H.C.; Hogue, H.B. A Brief History of the Emergence of Digital Government in the United States. In Digital Government: Principles and Best Practices; Pavlichev, A., Garson, G.D., Eds.; Idea Publishing Group: Hershey, PA, USA, 2004; pp. 16-33.

10. Estevez, E.; Janowski, T. Electronic Governance for Sustainable Development-Conceptual framework and state of research. Gov. Inf. Q. 2013, 30, S94-S109. [CrossRef]

11. Estevez, E.; Janowski, T. Landscaping Government Chief Information Officer Education. In Proceedings of the 46th Hawaii International Conference on System Sciences (HICSS-46), Wailea Maui, HI, USA, 7-10 January 2013; pp. 1684-1693.

12. Misra, H. E-Governance and Millennium Development Goals: Sustainable Development Perspective in Rural India. In Proceedings of the 6th International Conference on Theory and Practice of Electronic Governance (ICEGOV 2012), Abany, NY, USA, 22-25 October 2012; pp. 354-363. 
13. Mureşan, M. E-governance-A challenge for the regional sustainable development in Romania. In Proceedings of the 9th IFIP WG 8.5 International Conference on Electronic Government, EGOV 2010, Lausanne, Switzerland, 29 August-2 September 2010; Volume 6228, pp. 238-250.

14. Navarra, D.; Bianchi, C. Territorial Governance, E-Government and Sustainable Development Policy: A System Dynamics Approach. In Proceedings of the 12th IFIP WG 8.5 International Conference on Electronic Government, EGOV 2013, Koblenz, Germany, 16-19 September 2013; Volume 8074, pp. 14-25.

15. Grönlund, Å. ICT is Not Participation is Not Democracy-eParticipation Development Models Revisited. In Proceedings of the 1st IFIP WG 8.5 International Conference on Electronic Participation, ePart 2009, Linz, Austria, 1-3 September 2009; Volume 5694, pp. 12-23.

16. Müller, S.D.; Skau, S.A. Success factors influencing implementation of e-government at different stages of maturity: A literature review, (in en). Int. J. Electron. Gov. 2015, 7, 136-170. [CrossRef]

17. Schwab, K. The Fourth Industrial Revolution; Crown Business: Hong Kong, China, 2017.

18. Dahlström, P.; Desmet, D.; Singer, M. The Seven Decisions That Matter in a Digital Transformation: A CEO's Guide to Reinvention; McKinsey \& Company Digital McKinsey: Summit, NJ, USA, 2017; Available online: http:/ / www.mckinsev.com/business-flmctions/digital-mckinscv/ ourinsights/the-sevendccisions-that-matter-in-a-digital-transformation (accessed on 1 June 2018).

19. Maull, R.; Godsiff, P.; Mulligan, C. Transitioning to the Pull Economy: The case of the UK Railways. In Proceedings of the IEEE 2015 48th Hawaii International Conference on System Sciences (HICSS), Kauai, HI, USA, 5-8 January 2015; pp. 1285-1294.

20. Aundhe, M.D.; Narasimhan, R. Public private partnership (PPP) outcomes in e-government-A social capital explanation, (in English). Int. J. Public Sect. Manag. 2016, 29, 638-658. [CrossRef]

21. Bharosa, N.; Janssen, M.; Klievink, B.; Tan, Y.-H. Developing Multi-sided Platforms for Public-Private Information Sharing: Design Observations from Two Case Studies. In Proceedings of the 14th Annual International Conference on Digital Government Research, Quebec, QC, Canada, 17-20 June 2013; pp. 146-155.

22. Bharosa, N.; Voort, H.; Hulstijn, J.; Janssen, M.; Winne, N.; Wijk, R. Impose with Leeway: Combining an Engineering and Learning Approach in the Management of Public-Private Collaboration. In Proceedings of the 10th IFIP WG 8.5 International Conference on Electronic Government, EGOV 2011, Delft, The Netherlands, 28 August-2 September 2011; Volume 6846, pp. 392-403.

23. Richardson, C. Digital Government: Balancing Risk and Reward through Public/Private Partnerships. In Digital Government: Principles and Best Practices; Pavlichev, A., Garson, G.D., Eds.; Idea Publishing Group: Hershey, PA, USA, 2004; pp. 200-217.

24. Taher, M.; Yang, Z.; Kankanhalli, A. Public-private partnerships in e-government: Insights from Singapore cases. In Proceedings of the 16th Pacific Asia Conference on Information Systems (PACIS 2012), Ho Chi Minh City, Vietnam, 11-15 July 2012; pp. 1-11.

25. Yarlagadda, P.; Ahmed, S. Efficiency of Electronic Public Service Delivery in India: Public-Private Partnership as a Critical Factor. In Proceedings of the 1st International Conference on Theory and Practice of Electronic Governance (ICEGOV 2007), Macao, China, 10-13 December 2007; pp. 357-365.

26. Almuftah, H.; Weerakkody, V.; Sivarajah, U. Comparing and Contrasting e-Government Maturity Models: A Qualitative-Meta Synthesis. In Electronic Government and Electronic Participation: Joint Proceedings of Ongoing Research and Projects of IFIP WG 8.5 EGOV and ePart 2016; IOS Press: Guimarães, Portugal, 2016; Volume 23, pp. 69-79.

27. Andersen, K.N.; Henriksen, H.Z.; Medaglia, R. Maturity models in the age of digital diversity: Beyond the Layne \& Lee legacy. In Public Administration in the Information Age: Revisited; Snellen, I., Thaens, M., van de Donk, W., Eds.; IOS Press: Amsterdam, The Netherlands, 2012; pp. 205-220.

28. Das, A.; Singh, H.; Joseph, D. A Longitudinal Study of E-Government Maturity. In Proceedings of the 15th Pacific Asia Conference on Information Systems (PACIS 2011), Brisbane, Australia, 7-11 July 2011; pp. 1-12.

29. Lee, J. 10 year retrospect on stage models of e-Government: A qualitative meta-synthesis. Gov. Inf. Q. 2010, 27, 220-230. [CrossRef]

30. Wihlborg, E.; Hedström, K.; Larsson, H. e-Government for all-Norm-critical Perspectives and Public Values in Digitalization. In Proceedings of the 50th Hawaii International Conference on System Science (HICSS-50), Waikoloa Village, HI, USA, 4-7 January 2017; pp. 2549-2558. 
31. Li, F.; Nucciarelli, A.; Roden, S.; Graham, G. How smart cities transform operations models: A new research agenda for operations management in the digital economy, (in English). Prod. Plan. Control 2016, 27, 514-528. [CrossRef]

32. Bert, J.; Shin, Y.A.; Chalfont, B. Technology, Governance, and the Escalation of Ebola: Wicked Problems in Real Time. In Proceedings of the 16th Annual International Conference on Digital Government Research, Phoenix, AZ, USA, 27-30 May 2015; pp. 71-78.

33. Comfort, L.K.; Bert, J.; Song, J.E. Wicked problems in real time: Uncertainty, information, and the escalation of Ebola. Inf. Polity 2016, 21, 273-289. [CrossRef]

34. Kim, Y.; Zhang, J. Digital government and wicked problems. Gov. Inf. Q. 2016, 33, 769-776. [CrossRef]

35. Zhang, J.; Kim, Y. Digital government and wicked problems: Solution or problem? Inf. Polity 2016, 21, $215-221$. [CrossRef]

36. Weber, E.P.; Khademian, A.M. Wicked problems, knowledge challenges, and collaborative capacity builders in network settings. Public Adm. Rev. 2008, 68, 334-349. [CrossRef]

37. Newman, J.; Head, B.W. Wicked tendencies in policy problems: Rethinking the distinction between social and technical problems. Policy Soc. 2017, 36, 414-429. [CrossRef]

38. Wikepedia. Finite State Machine. Available online: https://en.wikipedia.org/wiki/Finite-state_machine (accessed on 19 December 2017).

(C) 2018 by the authors. Licensee MDPI, Basel, Switzerland. This article is an open access article distributed under the terms and conditions of the Creative Commons Attribution (CC BY) license (http://creativecommons.org/licenses/by/4.0/). 